\title{
Efficacy of Azoles Antifungals in Treatment of Pityriasis Versicolor
}

Jha S

\section{ABSTRACT}

Introduction: Pityriasis versicolor is superficial fungal infection. Topical drugs are often effective in treatment of limited disease while systemic drugs are more suitable in extensive cases The systemic triazole drugs, itraconazole and fluconazole have shown promising results at different doses. Aims: To assess the efficacy and safety of oral fluconazole combined with ketoconazole shampoo and oral itraconazole in the treatment of Pityriasis versicolor. Methods: The study was conducted at department of Dermatology at Nepalgunj Medical College from March 2019 to February 2020. Total 100 patients of both genders with Pityriasis versicolor were randomly allocated into two groups with 50 patients in each group. Patients in Group I received oral fluconazole $300 \mathrm{mg}$ a week for two consecutive weeks along with ketoconazole $2 \%$ shampoo twice weekly for two weeks while those in Group II received itraconazole $200 \mathrm{mg}$ daily for one week. Efficacy was assessed in terms of negative fungal hyphae. The drug is considered safe if no patients were withdrawn for clinical adverse effects or laboratory abnormalities. Results: In this study age ranged from 18 to 50 years with mean age of 31.1 years in Group I and 31.92 years in Group II. Efficacy was seen in $78 \%$ of Group I patients as compared to $54 \%$ in Group II patients at two weeks and 94\% in Group I and 90\% in Group II at four weeks. No significant adverse effects were reported in any of the group. Conclusion: Fluconazole along with ketoconazole shampoo is more effective than itraconazole in treatment of pityriasis versicolor with minimal side effects, at lesser cost.

Keywords: Efficacy, Fluconazole, Itraconazole, Ketoconazole, Pityriasis versicolor

Author:

1. Dr. Smita Jha

\section{Address for Correspondence:}

Dr. Smita Jha

Department of Dermatology

Nepalgunj Medical College and Teaching Hospital

Kohalpur, Banke, Nepal

Email:smi520437@gmail.com

\section{INTRODUCTION}

Pityriasis versicolor(PV) is common fungal infection of the stratum corneum caused by lipophilic yeast of Malassezia species. ${ }^{1}$ It is more common in warm and humid conditions. The genus Malassezia is part of the normal skin microflora. It needs predisposing factors for multiplication and subsequent conversion from the commensal yeast form to the mycelial phase. Factors associated with increased risk of acquiring PV are increased environmental humidity, application of oily preparation and creams, corticosteroid overuse, genetic predisposition, malnutrition and hyperhidrosis. ${ }^{2}$ It is clinically characterized by discrete, round to oval, hyperpigmented or hypopigmented slightly scaly macules, on the trunk, upper arms and face. ${ }^{3}$ History and clinical examination are enough to diagnose PV. The clinical diagnosis can be confirmed by direct microscopic examination of infected skin scraping treated with $10 \%$ potassium hydroxide $(\mathrm{KOH})$. Microscopic visualization of the fungi appears as short, thick hyphae with a large number of variously sized spores. ${ }^{4} \mathrm{PV}$ is generally asymptomatic, the greatest concern for patients leading to sought treatment is the unpleasant cosmetic appearance of the skin. Topical antifungals such as ketoconazole, miconazole or terbinafine are currently the first line of treatment for PV and systemic antifungals are recommended for severe or recalcitrant cases. ${ }^{5}$ Azole antifungal agents, causes inhibition of cytochrome P450 dependent lanosterol $14-\alpha$-demethylase, resulting in impaired sterol synthesis in fungal cell membranes to limit cell function and growth. ${ }^{6,7}$ This study is conducted to assess the efficacy and safety of oral fluconazole combined with ketoconazole shampoo and oral itraconazole in the treatment of PV.

\section{METHODS}

A hospital based comparative prospective study was conducted at department of Dermatology at Nepalgunj Medical College from March 2019 to February 2020. Patient of both genders, aged 18 to 50 years who had a clinical diagnosis of PV confirmed by mycological examination $(10 \% \mathrm{KOH})$ were included in the study. Patient with known sensitivity to itraconazole or fluconazole, who received any topical or systemic antifungal therapy during last one month, other superficial or systemic fungal infection, any history of renal or hepatic disease or malignancy, history of alcoholism, pregnant or lactating women and patients with other chronic illness (diabetes, hypertension) were excluded from the study. Data regarding the demographic parameters like age, gender and duration of complaints were recorded.

Eligible patients were randomly divided into two equal groups. Group I patients were asked to take oral fluconazole $300 \mathrm{mg}$ a week for two consecutive weeks along with ketoconazole $2 \%$ shampoo biweekly for two weeks, Group II patients were asked to take itraconazole $200 \mathrm{mg}$ daily for one week. Detailed 
history of every patient was taken, clinical and Wood's lamp examination was done, at first visit. Wood's lamp examination usually showed yellowish fluorescence of the involved skin. Patient were asked to follow up after two weeks and four weeks to assess the clinical and mycological improvement. At each visit, patients were examined regarding scaling, hyperpigmentation, hypopigmentation and pruritus.

Clinical evaluation was done by the naked eye appearance of the lesions, presence of re-pigmentation and disappearance of the lesions. The following criteria was adopted for this.

No improvement: Persistence of lesions and presence of scaling.

Moderate improvement: Lesions were less prominent and/or moderate decrease in scaling.

Marked improvement: Lesions appeared pale with presence/ or absence of mild scaling and disappearance of some of the lesions

Complete clinical cure: Complete disappearance of lesions.

Mycological evaluations which included direct $\mathrm{KOH}$ preparation from the most prominent lesion and Wood's lamp examination were also performed. Efficacy was defined in terms of mycological cures when the $\mathrm{KOH}$ examination was negative that is absence of fungal hyphae and spores.

The quantitative variables like age and duration of complain were calculated in means. The qualitative variables like gender, clinical improvement were calculated taking frequency and percentage. All the data were analyzed using SPSS version 25.Comparision of efficacy in two groups was done by chisquare test. A p-value of less than $0.05(p<0.05)$ was considered as significant.

Safety assessment was carried out in the two study groups at the end of second week and further re-assessed at the end of fourth week follow-up. Laboratory investigations such as complete blood count, liver and renal function tests were done at baseline and at the end of two weeks and subsequently repeated at the end of four weeks. Possible signs of side effects were recorded. Drug is considered to be unsafe if the laboratory parameters were deranged (not within normal range) or if the patient developed severe nausea, vomiting, headache or skin lesion other than that of PV which lead to disturbance in daily activities and needed medical intervention.

\section{RESULTS}

Total 101 patients aged 18 to 50 years were enrolled in our study. Patients of Group I $(n=50)$ received $300 \mathrm{mg}$ fluconazole as a single dose and repeated weekly for two weeks along ketoconazole $2 \%$ shampoo biweekly for 2 weeks, Group II $(n=50)$ patients received itraconazole $200 \mathrm{mg}$ daily for one week. One patient in Group I lost follow-up thus was excluded from study.

Mean age was 31.1 \pm 9.22 years in Group I and 31.92 \pm 8.98 years in Group II. Average duration of complaint was 12.84 months in Group I and 12.44 months in Group II, with a range of two months to 36 months in both groups. Among total study population 61(61\%) were male and 39(39\%) were female. Male to female ratio was 1.5:1.There were $31(62 \%)$ males and $19(38 \%)$ females in Group I while 30(60\%) male and $20(40 \%)$ females in Group II. There were no statistically significant ( $p>0.05$ ) differences regarding age, sex and duration of complaints between the two groups as shown in Table I.

$\begin{array}{lccc} & \text { Group I } & \text { Group II } & \text { P value } \\ \text { Gender } & 31 & 30 & >0.05 \\ \text { Male } & 19 & 20 & \\ \text { Female } & 31.1 & 31.9 & >0.05 \\ \text { Mean Age( years) } & 12.84 & 12.44 & >0.05 \\ \begin{array}{l}\text { Mean duration of } \\ \text { complain(months) }\end{array} & & \end{array}$

Table I: Characteristics of Patients

At four weeks $21(21 \%)$ of total patients showed complete clinical cure, $12(24 \%)$ in Group I and $9(18 \%)$ in Group II with no statistical significance ( $p>0.05)$. Eight $(8 \%)$ patients: $3(6 \%)$ in Group I and 5(10\%) in Group II had no clinical improvement as shown in Table II.

\begin{tabular}{lccc|}
\hline Clinical improvement & Group I & GroupII & Total \\
\hline Complete cure & 12 & 9 & 21 \\
& $(24 \%)$ & $(18 \%)$ & $(21 \%)$ \\
\hline Marked improvement & 21 & 14 & 35 \\
\hline Moderate improvement & $(42 \%)$ & $(28 \%)$ & $(35 \%)$ \\
\hline No improvement & 14 & 22 & 36 \\
\hline Total & $(28 \%)$ & $(44 \%)$ & $(36 \%)$ \\
& 3 & 5 & 8 \\
\hline
\end{tabular}

Table II: Clinical evaluation at 4 weeks

Mycological cure was seen in $39(78 \%)$ patients in Group I as compared to $27(54 \%)$ in Group II $(p=0.01)$ at two weeks. Efficacy was seen in 47(94\%) patients in Group I as compared to $45(90 \%)$ in Group II $(p=0.46)$ at four weeks as shown in Figure 1.

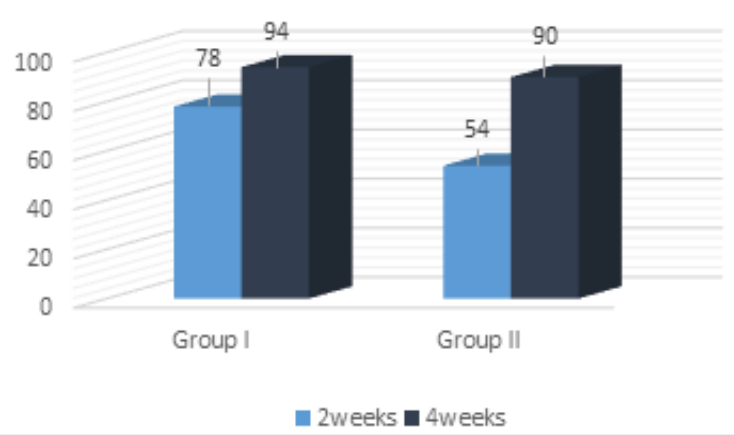

Figure 1: Mycological cure in Group I and Group II(\%) 
The laboratory parameters for all the patients were within normal limits in both groups before and after the treatment. There was no major side effect of the drugs except tolerable headache (three Patients) and gastrointestinal disturbances (10 patients) in few patients as shown in Table III. That resolved without any intervention and did not lead to discontinuation of the treatment. No patient developed any new skin rashes. No adverse effects were reported after completion of treatments.

$\left.\begin{array}{lcc|}\text { Adverse effects } & \begin{array}{c}\text { Group I } \\ \text { (Num \%) }\end{array} & \begin{array}{c}\text { Groupll } \\ \text { (Num \%) }\end{array} \\ \hline \text { Abdominal discomfort } & 1 & 3 \\ \hline \text { Diarrhea } & (2 \%) & (6 \%)\end{array}\right)$

Table III: Adverse effects in patients of Group I and Group II

\section{DISCUSSION}

PV is the fungal infection of superficial layer of skin commonly caused by M.sympodialis, M.furfur and M.globosa. ${ }^{8} \mathrm{PV}$ is common in the post-pubertal age where sebaceous glands are active and in the individuals who sweat more. ${ }^{9}$ As Malassezia species are endogenous to the skin flora, it is difficult to eradicate. Systemic therapy such as fluconazole and itraconazole can be used successfully in extensive and recurrent PV. ${ }^{10}$ In a study by Farschian et al has shown $93.33 \%$ mycological cure rate after completing two weeks treatment with $300 \mathrm{mg}$ fluconazole as single dose repeated weekly for two weeks. ${ }^{11}$ In another study by Bhogal et al mycological cure after four weeks of treatment was observed $82.2 \%$ and $64.4 \%$ with fluconazole $400 \mathrm{mg}$ single dose and $150 \mathrm{mg}$ per week dose for four weeks respectively. ${ }^{12}$ On the basis of these studies $300 \mathrm{mg}$ fluconazole as single dose repeated weekly for two weeks is observed to be the best.

There were several studies in which ketoconazole $2 \%$ shampoo was applied as treatment. In a study, by Tran cam V et al in 240 pityriasis versicolor patients were classified into three groups: Fluconazole $300 \mathrm{mg}$ a week and 2\% ketoconazole foam twice a week for two weeks (Category I), Itraconazole $200 \mathrm{mg}$ daily for one week (category II); Ketoconazole $2 \%$ foam daily for two weeks (Category III). After four weeks of treatment, the highest cure rate was observed in Category I (81.2\%), followed by Category II (66.3\%) andcategory III (60.0\%). It was reported in the study that the most effective regimen for PV patients is fluconazole $300 \mathrm{mg}$ per week combined with ketoconazole $2 \%$ twice a week for two weeks. ${ }^{13}$ Similarly in this study fluconazole $300 \mathrm{mg}$ per week combined with ketoconazole $2 \%$ twice weekly for two weeks is observed to be more effective.

In comparative study done by Badri et al, patients receiving fluconazole two doses 300mg given one week apart with patients taken an association of fluconazole (two doses $300 \mathrm{mg}$ given one week apart) and ketoconazole shampoo the first day. At the end of the study, there was no significant difference in clinical presentation and in improvement rate PV between fluconazole and association of fluconazole and ketoconazole shampoo. ${ }^{14}$

Studies have evaluated the efficacy of $400 \mathrm{mg}$ itraconazole administered once and for three days as compared to $200 \mathrm{mg}$ itraconazole for 5 or 7 days. ${ }^{15,16}$ While Kose et al demonstrated that a single $400 \mathrm{mg}$ dose was equivalent to $200 \mathrm{mg}$ for 7 days, ${ }^{16}$ Kokturk et al found a single $400 \mathrm{mg}$ dose to be ineffective, with itraconazole regimens of $400 \mathrm{mg}$ for three days and $200 \mathrm{mg}$ for 5 days both producing significantly greater mycological and complete cure $(p=0.001) .{ }^{15}$ Though in this study we opted to recommend $200 \mathrm{mg}$ itraconazole capsule for 7 days over $400 \mathrm{mg}$ itraconazole capsule for three days, as the patients had to take only one capsule a day which was more convienent with better compliance.

In the present study, the prevalence of disease was more among males (61\%) when compared to females (39\%), Ghosh et $\mathrm{al}^{8}$, Rao et $\mathrm{al}^{17}$ and Krishnan et $\mathrm{al}^{18}$ have also observed almost similar results with more prevalence of cases in males. This could be attributed to their profession and outdoor activities and easy accessibility of the health care services. In our research, fluconazole $300 \mathrm{mg}$ a week along with $2 \%$ ketoconazole shampoo twice a week for two weeks has proved to be significantly better than itraconazole 200mg daily for one weeks at two weeks regarding the mycological cure in the treated patients. This might be due to the combined antifungal action of oral fluconazole and ketoconazole shampoo. But at four weeks, there was not much difference demonstrated between mycological cure in both the treatment groups. The findings in our study is similar to other studies that shows mycological cure in patients treated for two weeks with oral fluconazole. ${ }^{11,12}$ The both regimen are safe. Itraconazole and fluconazole are well tolerated by most patients, the common side effects being gastrointestinal disturbances, which are mild and transient in nature. ${ }^{19,20,21,22}$ Therapy with fluconazole along with ketoconazole shampoo is preferable in view of single dose administration and lesser cost as compared to itraconazole with better results in short term. However studies have different results on short-term and long term effectiveness of both regimen. Residual dyschromia even after the successful treatment is problematic. ${ }^{10}$ Normalization of pigment following successful therapy is variable and may take months, depending on individual skin type and coincidental skin exposure. In this study also complete normalization of color was observed in some patients $(21 \%)$ only, as it mostly resolve within few months of treatment.

\section{LIMITATIONS}

The study was based on single center outpatient sample, the follow up of the patients was of short duration. So the findings of this comparative study may not reflect the exact scenario of general population. Further study is needed to assess the 
long term response to the treatments and to calculate relapse rate. We included only those cases who were confirmed by $\mathrm{KOH}$ examination; however, $\mathrm{KOH}$ examination is not $100 \%$ sensitive for $\mathrm{PV} .{ }^{23}$ This could result in the exclusion of $\mathrm{KOH}-$ negative cases. Dermoscopy evaluation of lesions might help in proper assessment of the disease severity in pretreatment, treatment and post treatment phase.

\section{CONCLUSION}

Although in our study we found significant superiority of fluconazole $300 \mathrm{mg}$ along with $2 \%$ ketoconazole shampoo twice weekly at initial two weeks but both treatment were similar at four weeks. Both fluconazole along with $2 \%$ ketoconazole shampoo and itraconazole were well tolerated and no serious drug-related events were reported in our study.

\section{REFERENCES}

1. Snekavalli R, Madhu R, Ramesh A. Clinico epidemiological and mycological study of pityriasis versicolor. 2018;6(6):1963-70.

2. Archana BR, Beena PM, Kumar SJljod. Study of the distribution of malassezia species in patients with pityriasis versicolor in Kolar Region, Karnataka. 2015;60(3):321.

3. Mendez-Tovar LJJCid. Pathogenesis of dermatophytosis and tinea versicolor. 2010;28(2):185-9.

4. Gupta AK, Batra R, Bluhm R, Faergemann JJDc. Pityriasis versicolor. 2003;21(3):413-29.

5. Saunte DM, Gaitanis G, Hay RJJFic, microbiology i. Malassezia-associated skin diseases, the use of diagnostics and treatment. 2020;10:112.

6. Elewski BEJJotAAoD. Mechanisms of action of systemic antifungal agents. 1993;28(5):S28-S34.

7. Faergemann J, Gupta A, Al Mofadi A, Abanami A, Shareaah AA, Marynissen GJAod. Efficacy of itraconazole in the prophylactic treatment of pityriasis (tinea) versicolor. 2002;138(1):69-73.

8. Ghosh SK, Dey SK, Saha I, Barbhuiya JN, Ghosh A, Roy AKJljod. Pityriasis versicolor: A clinicomycological and epidemiological study from a tertiary care hospital. 2008;53(4):182-5.

9. Schmidt AJC. Malassezia furfur: a fungus belonging to the physiological skin flora and its relevance in skin disorders. 1997;59(1):21-4.

10. Partap R, Kaur I, Chakrabarti A, Kumar BJD. Single-dose fluconazole versus itraconazole in pityriasis versicolor. 2004;208(1):55-9.

11. Farschian M, Yaghoobi R, Samadi KJJodt. Fluconazole versus ketoconazole in the treatment of tinea versicolor. 2002;13(2):73-6.

12. Bhogal CS, Singal A, Baruah MCJTJod. Comparative efficacy of ketoconazole and fluconazole in the treatment of pityriasis versicolor: A One Year Follow-up Study. 2001;28(10):535-9.
13. Van Tran Cam TNV, Hau KT, Le Huu D, Minh PPTJOaMJoMS. Efficacy of azole antifungal in treatment of pityriasis versicolor. 2019;7(2):272-4.

14. Badri T, Hammami H, Bzioueche N, Zouari B, Mokhtar IJTM. Comparative clinical trial: fluconazole alone or associated with topical ketoconazole in the treatment of pityriasis versicolor. 2016;94(2):107-11.

15. Kokturk A, Kaya T, Ikizoglu G, Bugdayci R, Koca AJJoDT. Efficacy of three short-term regimens of itraconazole in the treatment of pityriasis versicolor. 2002;13(4):185-7.

16. Köse O, Taştan HB, Gür AR, Kurumlu ZJJodt. Comparison of a single $400 \mathrm{mg}$ dose versus a 7-day $200 \mathrm{mg}$ daily dose of itraconazole in the treatment of tinea versicolor. 2002;13(2):77-9.

17. Rao GS, Kuruvilla M, Kumar P, Vinod VJIJoD, Venereology, Leprology. Clinico-epidermiological studies on tinea versicolor. 2002;68(4):208-9.

18. Ajaykrishnan DMTJIJD. Morphology and pigmentary variations of tinea. 2003;48(2):83-6.

19. Kowalsky SF, Dixon DJCp. Fluconazole: a new antifungal agent. 1991;10(3):179-94.

20. Grant SM, Clissold SPJD. Itraconazole. 1989;37(3):310-44.

21. Siddeshwara M, Jeevangi SR, Hogade AS, Manjunath $\mathrm{H}$, research. wJop. Comparative study of efficacy and tolerability of single dose itraconazole versus fluconazole in tinea versicolor. world Journal of pharmaceutical research. 2017;6(8):2351-63.

22. Jaswal R, Thami GP, Kanwar AJJjod, venereology, leprology. Fluconazole and itraconazole in pityriasis versicolor. 1999;65(5):216-8.

23. Shah A, Koticha A, Ubale M, Wanjare S, Mehta P, Khopkar UJljod. Identification and speciation of Malassezia in patients clinically suspected of having pityriasis versicolor. 2013;58(3):239. 